\title{
FP/FORM Versus FP/SAL Within Clinical Practice: An Updated Budget Impact Analysis in Asthma
}

Emily Farrington · Alison Saunders · Louise Heron · William Dunlop

Received: January 15, 2016 / Published online: March 26, 2016

(c) The Author(s) 2016. This article is published with open access at Springerlink.com

\begin{abstract}
Introduction: Pressurized metered-dose inhalers (pMDI) such as fluticasone propionate and salmeterol (FP/SAL) are commonly used for the treatment of asthma in the UK. Previously, a budget impact analysis demonstrated that use of FP and formoterol fumarate (FP/FORM) pMDI as an alternative to FP/SAL pMDI, would be a cost-saving option for the UK National Health Service (NHS). This budget impact analysis aimed to update the existing analysis with prescription volume data and real-world evidence since the introduction of FP/FORM to the UK market.
\end{abstract}

Enhanced content To view enhanced content for this article go to http://www.medengine.com/Redeem/ 8784F0600E48598D.

E. Farrington $\cdot$ L. Heron

Adelphi Values, Adelphi Mill, Bollington,

Macclesfield, Cheshire SK10 5JB, UK

A. Saunders

BioExcel Limited, Beckley Manor, Beckley, Oxford

OX3 9TG, UK

W. Dunlop ( $\square)$

Mundipharma International, Unit 194, Cambridge

Science Park, Milton Road, Cambridge CB4 OAB, UK

e-mail: will.dunlop@mundipharma.co.uk
Methods: Patient Data (IMS Information Solutions UK Ltd) moving annual total (MAT) August 2015 were used to ascertain the number of units of pMDI prescribed. Annual costs to the NHS in terms of drug, administration, monitoring and adverse event costs, were used to estimate the potential budget impact for FP/ FORM and FP/SAL. Costs were calculated for current prescription volumes $(12 \% \mathrm{FP} / \mathrm{FORM}$, $88 \% \mathrm{FP} / \mathrm{SAL}$ ), and for different prescription volume scenarios (FP/FORM at 0\%, 25\%, 50\% and 100\%). Real-world evidence and budget impact at a clinical commissioning group (CCG) level were also considered.

Results: Total annual costs per person year were less with FP/FORM (£625) than with FP/ SAL (£734). Annual costs to the NHS based on the current prescription volumes and clinical trial data were estimated at $£ 210.0 \mathrm{M}$, however, based on real-world evidence, costs were estimated at $£ 179.8 \mathrm{M}$. For all scenarios with increased FP/FORM prescription volumes, the annual total costs to the NHS decreased. This was reflected at a CCG level.

Conclusion: The use of FP/FORM as an alternative to FP/SAL can result in cost savings for the NHS when assessing drug, 
administration, monitoring and adverse events costs. The inclusion of data released since the launch of FP/FORM within the budget impact analysis demonstrates that the potential cost savings to the NHS that were previously published are being translated to clinical practice.

Funding: Mundipharma, UK.

Keywords: Asthma; Budget; Cost; Fluticasone propionate; Formoterol; Pulmonology; Salmeterol

\section{INTRODUCTION}

Currently, 5.4 million people in the UK are receiving treatment for asthma [1], which is associated with a substantial economic burden: the annual National Health Service (NHS) expenditure associated with treating and caring for asthma patients, in terms of drug costs, hospital admissions and general practitioner (GP) visits, was estimated to be approximately $£ 1$ billion in the UK [1].

There are a number of treatments available for asthma patients, and combination inhaled corticosteroid (ICS) and long-acting beta agonists (LABA) inhalers are recommended for the treatment of patients with asthma who are not controlled with ICS alone [2]. These combination inhalers are as effective at delivering the drug as individual component inhalers but may provide additional benefits in terms of safety (by ensuring the LABA component is not taken without the ICS component) and patient adherence [3, 4]. There are two main types of combination ICS/ LABA inhaler devices: the pressurized metered-dose inhaler (pMDI) and dry powder inhaler (DPI). Of these two main options, there may be benefits of using pMDIs over DPIs. For example, a recent study demonstrated that pMDIs, as opposed to DPIs, are associated with increased adherence in clinical practice, fewer exacerbations and lower health costs [5].

Within the UK, Seretide ${ }^{\circledR}$ (GlaxoSmithKline, Brentford, UK) (fluticasone propionate and salmeterol xinafoate; [FP/SAL]) has the greatest volume of ICS/LABA units prescribed for the treatment of patients diagnosed with asthma, accounting for $51.8 \%$ of the market, and is available within Accuhaler ${ }^{\circledR}$ (GlaxoSmithKline, Brentford, UK) (DPI) and Evohaler $^{\circledR}$ (GlaxoSmithKline, Brentford, UK) (pMDI) device types [6]. flutiform $^{\circledR}$ (Jagotec AG, Cambridge, UK) (FP and formoterol fumarate; FP/FORM) pMDI entered the UK market in 2013, and currently accounts for $4.6 \%$ of overall ICS/LABA units prescribed for patients with an asthma diagnosis [6].

Prior to the introduction of FP/FORM, a budget impact model was developed to evaluate the impact for the NHS of using FP/ FORM as an alternative treatment to FP/SAL [7]. The comparable efficacy of FP/FORM to FP/SAL had been previously demonstrated in patients aged $\geq 18$ years with persistent asthma for $\geq 6$ months in an open-label, randomized, active-controlled, parallel-group, multicenter, Phase III non-inferiority study [8, 9]. Based on projected FP/FORM uptake scenarios, the previous model demonstrated that switching from $\mathrm{FP} / \mathrm{SAL}$ to $\mathrm{FP} / \mathrm{FORM}$ could result in savings to the NHS [7]. Since the introduction of FP/ FORM to the UK market, data demonstrating the effectiveness and resource use impact of FP/ FORM in real-world settings have become available, which may impact upon the previously modeled outputs [10]. The real-world data showed that patients who switched from FP/SAL to FP/FORM had fewer asthma consultations (with or without prescription of oral steroids) (1.4 for FP/FORM 
versus 1.8 for $\mathrm{FP} / \mathrm{SAL} ; p=0.001$ ) and also confirmed that FP/FORM is non-inferior to FP/ SAL in terms of preventing severe exacerbations [10].

\section{Aims}

The aims of this update to the budget impact analysis were twofold: to update the existing budget impact model with prescription volume data since the introduction of FP/FORM to the UK market, and to compare the results of the budget impact model base-case with newly available real-world evidence to evaluate the use of FP/FORM in clinical practice, as compared to FP/SAL.

\section{METHODS}

\section{Update of Budget Impact Model}

The full methodology of the existing budget impact model has been published previously [7]. In addition to the previous analyses, the updated model also considers the inputs of adverse events (AEs) within the base-case scenario, instead of inclusion in a scenario analysis. Furthermore, the update considers real-world evidence, which has become available since FP/FORM entered the market.

\section{Comparators}

As with the previous model, Seretide Evohaler (FP/SAL) was considered to be the most appropriate comparator to FP/FORM for analysis of the budget impact to the NHS as it is in the same pMDI device type [7]. Due to differences in device handling, it was assumed patients were less likely to switch between DPIs and pMDIs, thus DPIs were excluded from the analysis. As discussed in the previous publication [7], in the UK it is unlikely that patients would be switched from BDP/FORM to FP/FORM, thus BDP/FORM was excluded from the analysis.

Sirdupla $^{\mathrm{TM}}$ (Mylan, Hatfield, UK), a generic FP/SAL launched in June 2015 in the UK, was not considered within the model. This is because FP/SAL is listed as Category $\mathrm{C}$ within the drugs tariff in the UK [11], meaning that generic prescription prices are linked to the originator brand list price [12]. Moreover, Sirdupla is only available in two doses (125 and $250 \mu \mathrm{g}$ ), and due to the recent launch, uptake of Sirdupla was unknown.

\section{Analysis Approach}

A budget impact calculation based on drug-related and monitoring costs was performed to estimate the impact of using either FP/FORM or FP/SAL in terms of cost to the NHS, in patients with asthma (Table 1). The impact was assessed over a 1 year time horizon, in line with the standard timeframe for NHS budgeting in the UK. The budget impact was estimated assuming that the total number of units of pMDIs prescribed each year will remain constant but that FP/FORM may be used as an alternative to $\mathrm{FP} / \mathrm{SAL}$ in a certain proportion of patients.

Drug-related costs included drug acquisition costs, monitoring costs, and administration costs; these were based on product labels, UK reference costs and global initiative for asthma (GINA) guidelines. AE-associated costs were based on rates from the head-to-head non-inferiority study of FP/FORM versus $\mathrm{FP} /$ SAL [8], a GP visit and a 1 week course of antibiotics (Augmentin) for infections and infestations. 


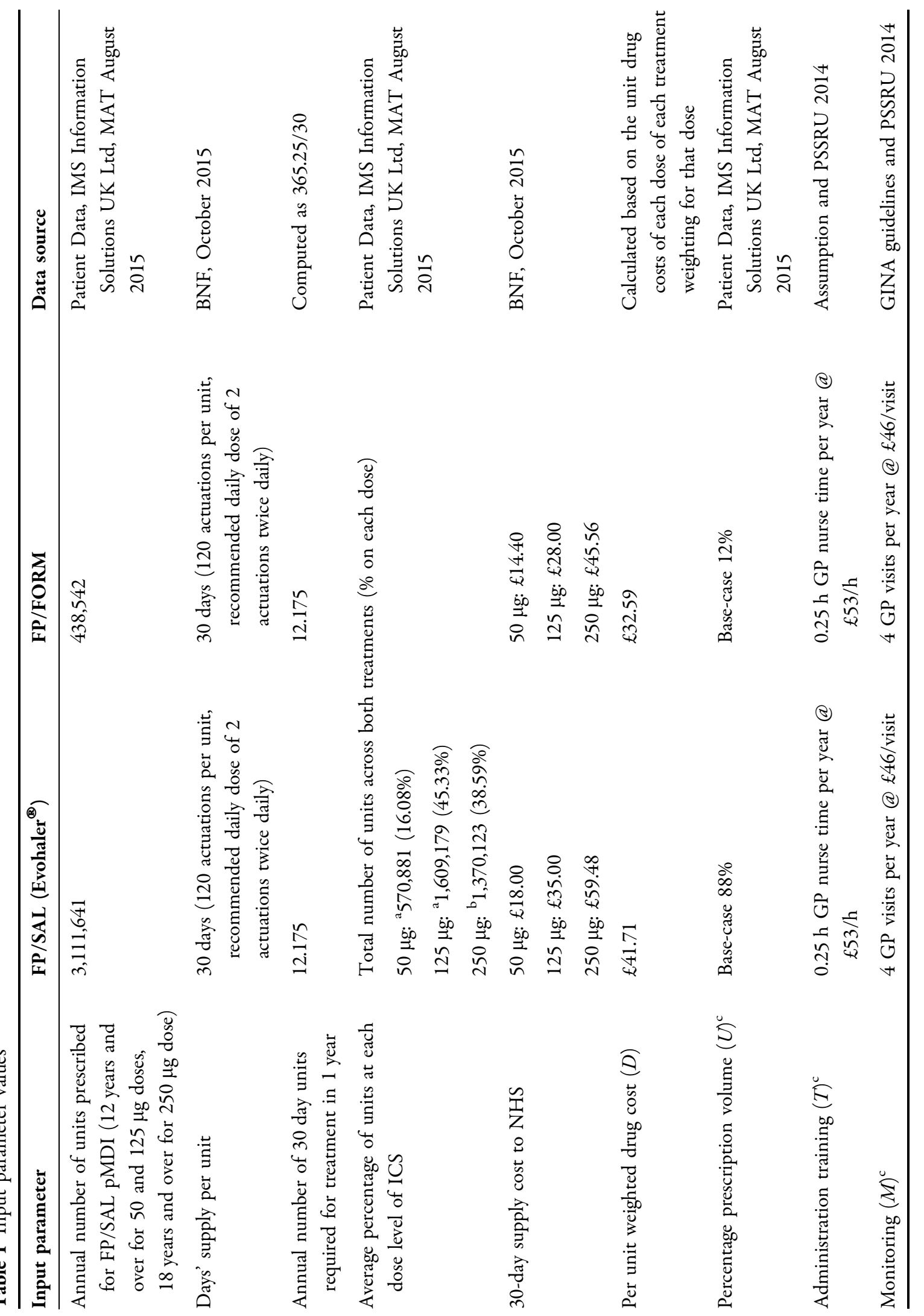




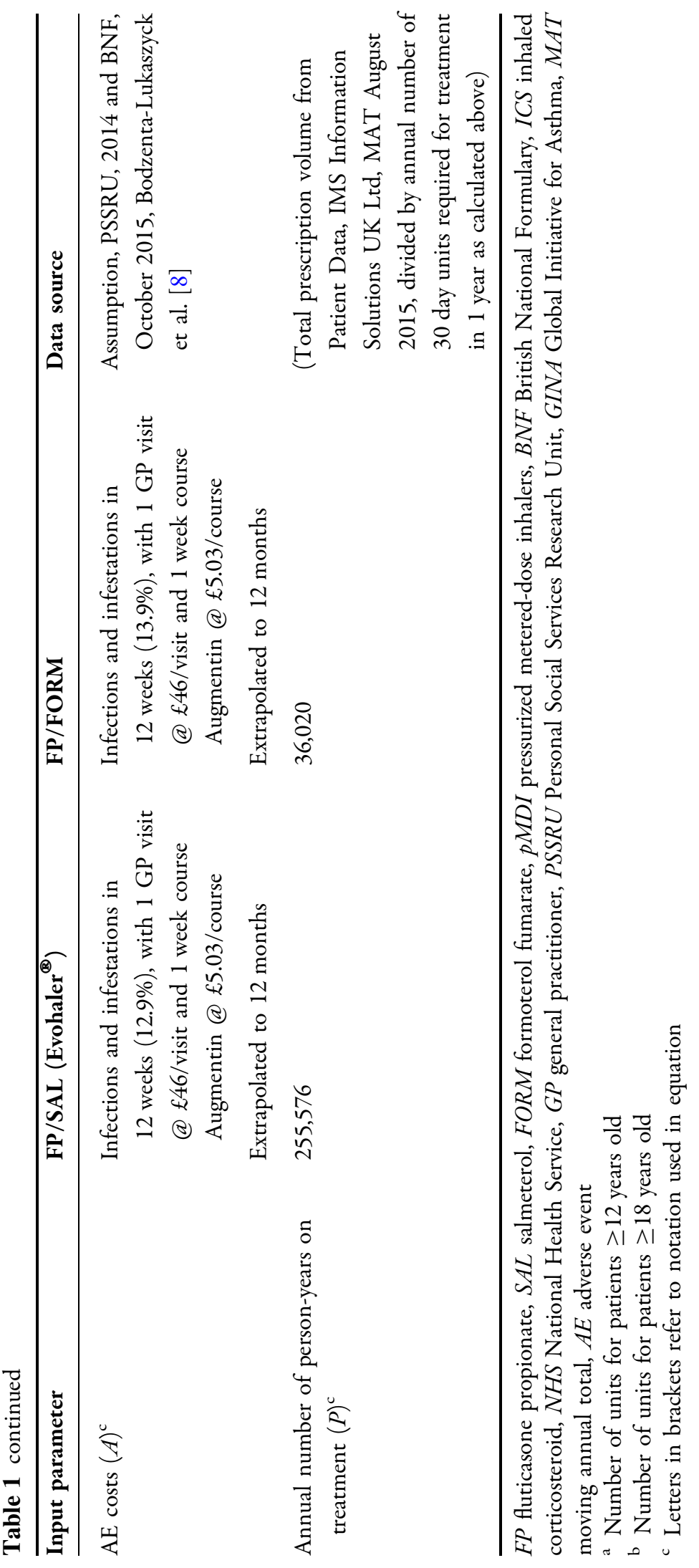


As per the previous model, secondary endpoints such as disease-related outcomes and associated costs were not included, as the head-to-head non-inferiority trial for FP/FORM versus FP/SAL demonstrated no significant differences in terms of these secondary efficacy endpoints [8].

\section{Input Parameters}

\section{Base-Case}

Annual Units Prescribed Patient Data were used to ascertain the number of units prescribed of FP/FORM and FP/SAL for patients with an asthma diagnosis within the UK [6]. Data were obtained from MAT August 2015 data, covering units prescribed from 1 September 2014 to 31 August 2015 [6]. The Patient Data contain details of a patient's age and their diagnosis (asthma or chronic obstructive pulmonary disease [COPD]) at any point in the patients' primary care medical record (in this case, a patient would be classified as an asthma patient if they have ever had a diagnosis of asthma recorded (and no diagnosis of COPD) or had a spirometry test which confirms reversibility) [6]. Therefore, specific details on different age groups of patients were available for use in this analysis.

The number of FP/FORM pMDI units prescribed for patients with an asthma diagnosis was obtained from the Patient Data [6]. In accordance with the label, data for the 50 and $125 \mu \mathrm{g}$ doses were taken from patients aged 12 and over, whereas units prescribed for $250 \mu \mathrm{g}$ were taken from those aged 18 and over. The number of FP/SAL pMDI units prescribed was taken from the corresponding age groups for the Evohaler device (Table 1).

Drug-Related Costs Drug acquisition costs were calculated using unit costs from the
British National Formulary (BNF), October 2015 for the following doses: 50, 125, and $250 \mu \mathrm{g}$ [13]. The average prescription volume of each dose $(50,125$, and $250 \mu \mathrm{g})$ across both therapies (FP/FORM and FP/SAL) was calculated to provide weighted costs for each dose of the two therapies [Table 1, (referred to as " $D$ " in the calculation)]. The number of units prescribed per patient per year was calculated as number of days per year divided by the days supplied per unit $(365.25 / 30=12.175$ units) (Table 1$)$. Total relative costs for each pMDI were multiplied by the number of units prescribed per patient per year to provide total drug acquisition costs per pMDI.

It was assumed that administration costs would not differ between FP/FORM and FP/SAL as the device type (pMDI) is the same for both. Administration costs were assumed to require $0.25 \mathrm{~h}$ of GP nurse time for training across both device types (Table 1).

It was assumed that monitoring costs would not differ between pMDIs as GINA guidelines (2015) state that patients should be seen 1-3 months after initiation of any treatment and every 3-12 months after that [2]. To be consistent with the previous budget impact analysis [7] and to be in line with the new GINA guidelines, it was assumed that patients were seen four times per year and costed according to the Personal Social Services Research Unit (PSSRU) for GP visits (Table 1) [14]. However, as there is uncertainty over the level of consultations due to the broad range given in the GINA guidelines, this assumption was tested using the real-world data, which reported the average number of asthma consultations, in a scenario analysis.

$\mathrm{AE}$ rates were based on infestations and infections data from a 12-week head-to-head non-inferiority trial FP/FORM (13.9\%) versus $\mathrm{FP} / \mathrm{SAL}(12.9 \%)$ (the two treatment groups 
overall had similar safety and tolerability profiles, and infections and infestations were the most commonly reported $\mathrm{AE}$ ) [8]. The cost per $\mathrm{AE}$ was assumed to be equivalent between treatments and based on one GP visit (costed according to PSSRU) and one course of Augmentin (costed according to BNF, October 2015) $[13,14]$. Costs were estimated according for 12 weeks and extrapolated to 1 year based on the assumption that AEs would continue at the same rate throughout the year (Table 1).

\section{Budget Impact Analysis}

\section{Cost Per Person Year}

Costs per person year were calculated based on the sum of the total drug-related and monitoring costs (Table 1).

\section{Annual Costs for the NHS}

Annual costs for the NHS were calculated based on the multiplication of drug acquisition, training, AE and monitoring cost estimates per person year with the person-years on each treatment. The base-case considered the current scenario: FP/FORM at a prescription volume of $12 \%$ and $\mathrm{FP} / \mathrm{SAL}$ prescription volume of $88 \%$ [of the total patients being prescribed either FP/FORM or FP/SAL in the appropriate age groups (Table 1)]. Further prescription volume scenarios were considered, with prescription volumes of $\mathrm{FP} / \mathrm{FORM}$ at $0 \%, 25 \%$, $50 \%$ and $100 \%$.

\section{Calculation}

The total annual costs for treatment per person per year $\left(C_{i}\right.$, $[i=$ treatment, where $i=1$ refers to $\mathrm{FP} / \mathrm{SAL}, \quad i=2$ refers to $\mathrm{FP} / \mathrm{FORM}]$ ) were calculated by summing the weighted drug acquisition costs $(D)$, GP visits for monitoring
$(M)$, nurse time for administration training $(T)$, and $\mathrm{AE}(A)$ costs (see Table 1 ):

$C_{i}=\sum(D, M, T, A)$

To assess budget impact to the NHS, the total budget impact (TBI) associated with FP/FORM and FP/SAL was calculated as follows (where $P_{i}$ is the annual number of person-years on treatment and $U_{i}$ is the percentage prescription volume; $[i=1$ refers to $\mathrm{FP} / \mathrm{SAL}, i=2$ refers to $\mathrm{FP} /$ FORM]):

$\mathrm{TBI}=\left(\left(P_{1}+P_{2}\right) U_{1} C_{1}\right)+\left(\left(P_{1}+P_{2}\right) U_{2} C_{2}\right)$

\section{CCG Level Data}

The average cost for a typical clinical commissioning group (CCG) in the UK was also considered for the current prescription volume and all other scenarios in which FP/FORM prescription volume is $0 \%, 25 \%, 50 \%$ and $100 \%$. There are 209 CCGs in England, each commissioning care for an average of 250,000 people, which is approximately $0.39 \%$ of the total UK population of 64.6 million [15, 16]. Therefore, the total annual NHS-level budget impact for FP/ FORM and FP/SAL was multiplied by $0.39 \%$ to provide the estimated CCG level budget impact.

\section{Scenario 1: Real-World Data}

Scenario 1 utilized monitoring costs from a UK retrospective observational real-world study which included FP/FORM and FP/SAL, replacing the estimated number of consultations based on the GINA guidelines used for the base-case with the actual average number of consultations that occurred over 1 year in the real-world study) (Table 2) [10]. This scenario analysis was applied to each of the prescription volume analyses described above. 
Table 2 Input parameter values for real-world evidence scenario analysis

\begin{tabular}{lccc}
\hline Input parameter & FP/SAL $\left(\right.$ Evohaler $\left.^{\circledR}\right)$ & FP/FORM & Data source \\
\hline Scenario 1: real-world evidence & & \\
Monitoring $(M)^{\text {a }}$ & 1.8 GP visits per year & 1.4 GP visits per year & Lim et al. [10] and PSSRU \\
& $@ £ 46 /$ visit & @ $£ 46 /$ visit & 2014 \\
\hline
\end{tabular}

FP fluticasone propionate, SAL Salmeterol, FORM formoterol fumarate, GP general practitioner, PSSRU Personal Social Services Research Unit

a Letters in brackets refer to notation used in equation

\section{Compliance with Ethics Guidelines}

This article does not contain any new studies with human or animal subjects performed by any of the authors.

\section{RESULTS}

\section{Base-Case Analysis}

\section{Cost Per Person Year}

Annual drug acquisition costs were lower with FP/FORM (£397) than with FP/SAL (£508), while annual administration training $(£ 13)$ and monitoring costs $(£ 184)$ were the same for both combination therapies. AE costs were very slightly higher with FP/FORM (£31) than FP/SAL (£29). The cost per person year based on the current prescription volume data was $£ 109$ less with FP/FORM (£625) than with FP/SAL (£734) (Fig. 1).

\section{Cost to NHS}

Annual costs to NHS are presented in Fig. 2. The costs to the NHS based on the current prescription volume (FP/FORM 12\%, FP/SAL $88 \%$ ) were estimated at $£ 210.0 \mathrm{M}$. With increased FP/FORM prescription volume, the total costs of the FP/FORM and FP/SAL market to the NHS decreased to $£ 206.0 \mathrm{M}, £ 198.1 \mathrm{M}$ and $£ 182.2 \mathrm{M}$, for $\mathrm{FP} / \mathrm{FORM}$ volume of $25 \%$,

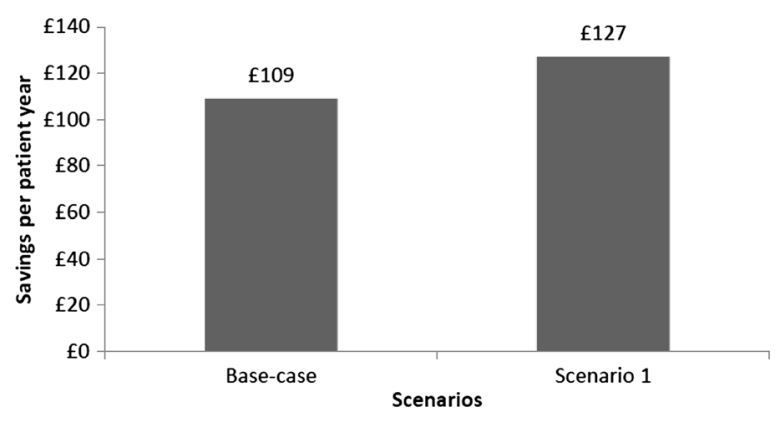

Fig. 1 Annual savings per person year associated with using FP/FORM as an alternative to FP/SAL. FP fluticasone propionate, FORM formoterol fumarate, $S A L$ salmeterol

$50 \%$ and $100 \%$, respectively. However, with $0 \%$ prescription of $\mathrm{FP} / \mathrm{FORM}$, the budget impact to the NHS was calculated at $£ 213.9 \mathrm{M}$. The savings compared to no use of FP/FORM were $£ 3.9 \mathrm{M}, £ 7.9 \mathrm{M}, £ 15.8 \mathrm{M}, £ 31.7 \mathrm{M}$ at $12 \%, 25 \%, 50 \%, 100 \%$ prescription volume shares, respectively.

Upon scaling the national-level data to the average size of a CCG within the UK $(250,000$ people, or $0.39 \%$ of the total UK population of 64.6 million) the budget impact was estimated at approximately $£ 812.7 \mathrm{~K}$ for the base-case scenario. With increased $\mathrm{FP} / \mathrm{FORM}$ prescription volumes of $25 \%, 50 \%$ and $100 \%$, the budget impact at a CCG level was calculated at $£ 797.2 \mathrm{~K}, £ 766.5 \mathrm{~K}$ and $£ 705.0 \mathrm{~K}$, respectively. However, with $0 \%$ prescription of $\mathrm{FP} / \mathrm{FORM}$, the budget impact at CCG level was calculated 


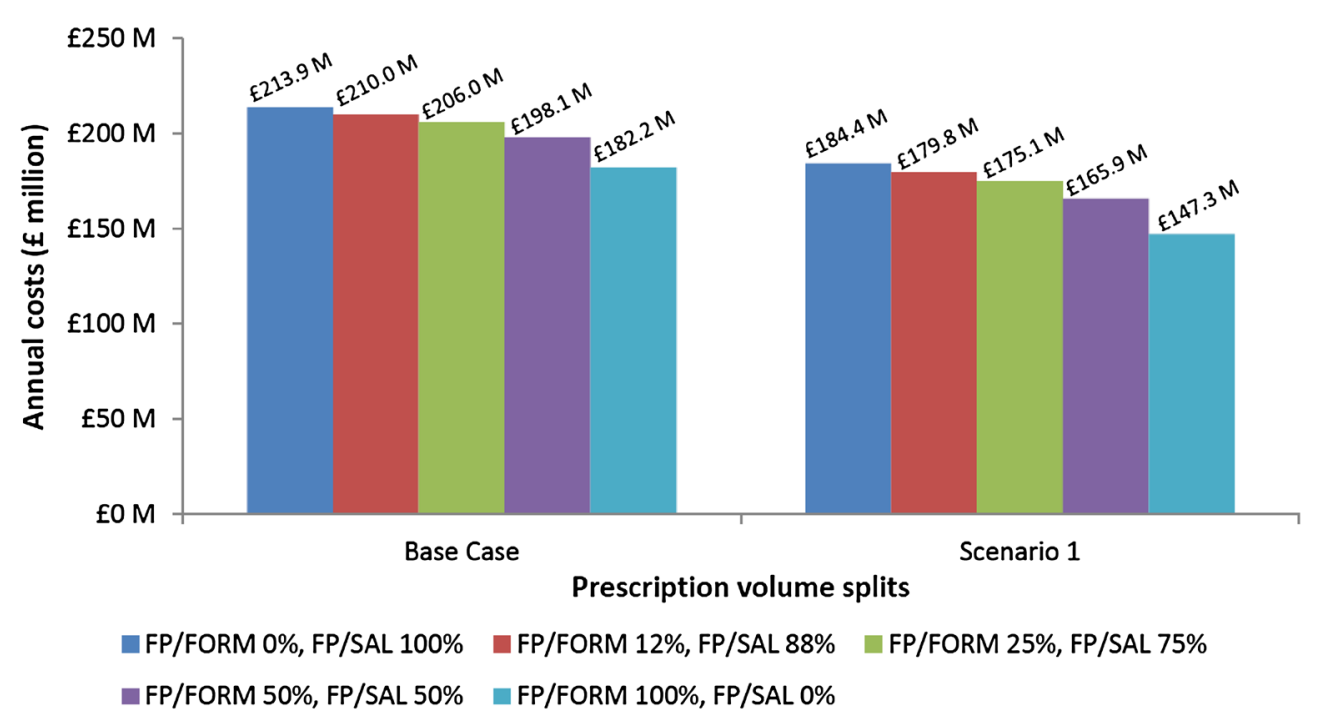

Fig. 2 Annual costs to the NHS at current prescription volume scenario and alternative scenarios. NHS National Health Service, FP fluticasone propionate, FORM formoterol fumarate, SAL salmeterol

at $£ 827.9 \mathrm{~K}$. The savings compared to no use of $\mathrm{FP} / \mathrm{FORM}$ were $15.2 \mathrm{~K}, 30.7 \mathrm{~K}, 61.4 \mathrm{~K}$ and $122.9 \mathrm{~K}$ at $12 \%, 25 \%, 50 \%, 100 \%$ prescription volume shares, respectively.

\section{Scenario Analyses}

\section{Scenario 1: Real-World Data}

This scenario considered monitoring cost data from a UK real-world study [10]. In comparison to the base-case, inclusion of real-world data resulted in decreased costs to the NHS in all prescription volume scenarios considered (Fig. 2). This was driven by the differences in the monitoring costs.

TBI to the NHS decreased from $£ 179.8 \mathrm{M}$ at a $12 \% \mathrm{FP} / \mathrm{FORM}$ prescription volume to $£ 175.1 \mathrm{M}$, $£ 165.9 \mathrm{M}$ and $£ 147.3 \mathrm{M}$ at $25 \%, 50 \%$ and $100 \%$ FP/FORM prescription volume, respectively. When FP/FORM prescription volume was decreased to $0 \%$, the total cost to the NHS increased to $£ 184.4 \mathrm{M}$. The savings compared to no use of FP/FORM were $£ 4.6 \mathrm{M}, £ 9.3 \mathrm{M}, £ 18.5 \mathrm{M}$,
$£ 37.1 \mathrm{M}$ at $12 \%, 25 \%, 50 \%, 100 \%$ prescription volume shares, respectively.

Using the current prescription volumes, cost per person year was calculated at $£ 505$ for $\mathrm{FP} /$ FORM and $£ 632$ for FP/SAL, saving $£ 127$ with FP/FORM (Fig. 1).

When considering data at CCG level at the current prescription volumes, the budget impact was calculated as $£ 696.0 \mathrm{~K}$. The budget impact decreased with increasing FP/FORM prescription volumes to: $£ 677.8 \mathrm{~K}, £ 641.9 \mathrm{~K}$ and $£ 570.0 \mathrm{~K}$ at $25 \%, 50 \%$, and $100 \% \mathrm{FP} / \mathrm{FORM}$ prescription. However, with $0 \%$ prescription of FP/FORM, the budget impact at CCG level is estimated at $£ 713.7 \mathrm{~K}$. The savings compared to no use of $\mathrm{FP} / \mathrm{FORM}$ were $17.7 \mathrm{~K}, 35.9 \mathrm{~K}, 71.8 \mathrm{~K}$, $143.7 \mathrm{~K}$ at $12 \%, 25 \%, 50 \%, 100 \%$ prescription volume shares, respectively.

\section{DISCUSSION}

This study demonstrates that the use of $\mathrm{FP} /$ FORM as an alternative to FP/SAL can result in 
cost savings compared to FP/FORM not being available (based on 12-100\% prescription volumes of FP/FORM) for the NHS when assessing drug, administration, monitoring and AE costs.

The results from this analysis are consistent with those of the previous analysis [7]. In addition, the specific description of the Patient Data used to ascertain prescription volume has been improved as compared to that used in the previous publication. A recent case study demonstrated that in one Northern Ireland community, $88.3 \%(n=53)$ of patients were successfully switched from the FP/SAL Evohaler to FP/FORM, which resulted in savings of $£ 111.89$ per patient over an 18-month period [17]. Furthermore, in August 2015, FP/FORM prices decreased (after the publication of the case study). This is likely to further increase savings associated with a successful switch to FP/FORM. Given that the proportion of patients within the community who underwent a successful switch reached $88.3 \%$ of patients in the case study from Northern Ireland [17], the scenario presented in this paper with an FP/ FORM share of $50 \%$ is a realistic scenario for clinical practice.

Consideration of data from Lim et al. included within the real-world evidence scenario (scenario 1) resulted in a saving to the NHS, indicating that the use of FP/FORM as an alternative to $\mathrm{FP} / \mathrm{SAL}$ is associated with greater savings in clinical practice, than the costs predicted by the RCT data, subject to a successful switch [10]. The difference in costs between the base-case and the real-world scenario was driven by monitoring costs. Patients in the Lim et al. study had fewer GP visits than recommended by the GINA guidelines at the time of the study [10]. However, there were still fewer GP consultations associated with FP/FORM than
FP/SAL and, therefore, less resource consumption. As the patient population on FP/FORM was the same as that on FP/SAL it is likely that this difference is therapy related, rather than driven by behavior.

Further to this, data from Lim et al. demonstrated that FP/FORM is associated with a lower percentage of severe exacerbations than FP/SAL [10, 18]. This suggests that FP/FORM may be associated with fewer hospitalizations and requirements of rescue therapy than FP/SAL [10]. However, due to the limited detail within the published Lim et al. data, direct comparisons to the RCT data for the base-case scenario could not be made and as such, exacerbation data from Lim et al. were not considered within the model. Furthermore, separate analyses based on this dataset which have been presented at a conference demonstrated that switching patients from $\mathrm{FP} /$ SAL to FP/FORM results in non-inferior prevention of severe asthma exacerbations but at a statistically significant lower cost (total respiratory-related healthcare cost per patient was $£ 64$ lower for FP/FORM), which is in line with the findings of our analysis [18].

Another recent study in Spain noted that when comparing the price of FP/FORM with other combinations of ICS/LABA, the price of FP/FORM was significantly lower [19]. Furthermore, over the first 3 years, the Spanish National Health Service is expected to save nearly $€ 4.4$ million from its pharmacy budget with the introduction of FP/FORM for the treatment of moderate to severe asthma [19]. Furthermore, a non-interventional study on safety and effectiveness in Germany reinforced the findings from the clinical trials by demonstrating that FP/FORM improves lung function, asthma control, and asthma related quality of life in a real-world setting: there was a statistically significant improvement compared 
with baseline in asthma control (as measured by the Asthma Control Test) of patients being treated with FP/FORM over a 3-month period, and there were also improvements seen in terms of quality of life and other secondary efficacy measures [20].

As noted, our analysis demonstrates that an increased uptake of FP/FORM can result in overall cost savings to the NHS without adversely affecting clinical outcomes; there have been several studies comparing FP/FORM with FP/SAL $[8,9]$ and Phase III clinical trials have demonstrated that FP/FORM is at least as effective as, and has a faster onset of action, than FP/SAL [8, 9]. In addition, FP/FORM has been recommended as a suitable alternative to other first-line ICS/LABA treatments, including FP/SAL and BUD/FORM, by the Midlands Therapeutics Review and Advisory Committee [21]. The Scottish Medicines Consortium has also recommended treatment with FP/FORM in patients for which FP and FORM are appropriate choices of ICS and LABA [22]. The National Institute for Healthcare and Clinical Excellence recommend that for patients in whom treatment with an ICS is considered appropriate, the least costly product should be chosen (within its marketing authorization) [23]. In comparison to $\mathrm{FP} / \mathrm{SAL}, \mathrm{FP} / \mathrm{FORM}$ is likely to be the least costly option in terms of list price, and overall budget impact to the NHS.

\section{CONCLUSIONS}

This updated budget impact analysis demonstrates that the use of FP/FORM within the UK market results in potential cost savings to the NHS. Since the launch of FP/FORM, real-world evidence has been generated which corroborates the results of clinical trials and when these data are included within the budget impact analysis, it demonstrates that the potential cost savings to the NHS that were previously published are likely to translate into meaningful changes in clinical practice.

\section{ACKNOWLEDGMENTS}

Sponsorship, article processing charges, and the open access charge for this study were funded by Mundipharma, UK. All authors had full access to all of the data in this study and take complete responsibility for the integrity of the data and accuracy of the data analysis. All named authors meet the International Committee of Medical Journal Editors (ICMJE) criteria for authorship for this manuscript, take responsibility for the integrity of the work as a whole, and have given final approval for the version to be published.

Disclosures. William Dunlop is an employee of Mundipharma International Ltd, United Kingdom. Alison Saunders is an employee of BioExcel Ltd, and received funding from Mundipharma International Ltd to support the research. Emily Farrington is an employee of Adelphi Values Ltd, UK. Adelphi Values Ltd received funding from Mundipharma International Ltd to support this research. Louise Heron is an employee of Adelphi Values Ltd, UK. Adelphi Values Ltd received funding from Mundipharma International Ltd to support this research. Medical writing assistance was provided by Emily Farrington and Louise Heron from Adelphi Values LTD, UK. Adelphi Values Ltd received funding from Mundipharma International Ltd to support this research.

Compliance with Ethics Guidelines. This article does not contain any new studies with 
human or animal subjects performed by any of the authors.

Open Access. This article is distributed under the terms of the Creative Commons Attribution-NonCommercial 4.0 International License (http://creativecommons.org/licenses/ by-nc/4.0/), which permits any noncommercial use, distribution, and reproduction in any medium, provided you give appropriate credit to the original author(s) and the source, provide a link to the Creative Commons license, and indicate if changes were made.

\section{REFERENCES}

1. Asthma UK. Asthma facts and FAQs. Available from: http://www.asthma.org.uk/asthma-facts-and-statist ics. Oct, 2015.

2. From the global strategy for asthma management and prevention, Global Initiative for Asthma (GINA) 2015. Available from: http://www. ginasthma.org/. Dec, 2015.

3. Barnes P. Scientific rationale for using a single inhaler for asthma control. Eur Respir J. 2007;29(3):587-95.

4. Marceau C, Lemière C, Berbiche D, Perreault S, Blais L. Persistence, adherence, and effectiveness of combination therapy among adult patients with asthma. J Allergy Clin Immunol. 2006;118(3):574-81.

5. Sicras-Mainar A, Collar J, Ferrer V, Navarro R, editors. Device inhalators in asthma and their impact on treatment adherence. PMD102. Value Health. 2015;18(7):A362.

6. Patient Data, IMS Information Solutions UK Ltd, MAT August 2015.

7. Dunlop W, Heron L, Fox G, Greaney M. Budget impact analysis of a fixed-dose combination of fluticasone propionate and formoterol fumarate (FP/FORM) in a pressurized metered-dose inhaler (pMDI) for asthma. Adv Therapy. 2013;30(10):933-44.

8. Bodzenta-Lukaszyk A, Dymek A, McAulay K, Mansikka H. Fluticasone/formoterol combination therapy is as effective as fluticasone/salmeterol in the treatment of asthma, but has a more rapid onset of action: an open-label, randomized study. BMC Pulm Med. 2011;11(1):28.

9. Aalbers R, Brusselle G, McIver T, Grothe B, Bodzenta-Lukaszyk A. Onset of bronchodilation with fluticasone/formoterol combination versus fluticasone/salmeterol in an open-label, randomized study. Adv Therapy. 2012;29(11):958-69.

10. Lim D, Small I, Wolfe S, Hamill J, Gruffydd-Jones K, Daly C, Price D. Real-world effectiveness of changing fixed-dose combination therapy from Seretide ${ }^{\circledR}$ MDI to FLUT/FORM MDI in UK asthma patients. Respiratory Effectiveness Group; 2014. Abstract 35.

11. National Health Service (NHS). Electronic Drug Tariff October 2015. Available from: http://www. drugtariff.nhsbsa.nhs.uk/\#/00252860-FA/FA002519 32/Home. Dec, 2015.

12. Pharmaceutical Services Negotiating Committee (PSNC). Dispensing factsheet: using the drug tariff. Available from: http://psnc.org.uk/wp-content/ uploads/2013/07/CPN-Factsheet-Jan-15-for-website. pdf. Oct, 2015.

13. Joint Formulary Committee. British National Formulary. London: BMJ Group and Pharmaceutical Press. Available from: http://www. medicinescomplete.com. Dec, 2015.

14. Personal Social Services Research Unit (PSSRU). Unit costs of health and social care 2014. Available from: http://www.pssru.ac.uk/projectpages/unit-costs/2014/. Dec, 2015.

15. NHS Clinical Commissioners. About CCGs. Available from: http://www.nhscc.org/ccgs/. Nov, 2015.

16. Office for National Statistics. Overview of the UK Population 2015. Available from: http://www.ons. gov.uk/ons/rel/pop-estimate/population-estimatesfor-uk-england-and-wales-scotland-and-northernireland/mid-2014/sty-overview-of-the-uk-popula tion.html. Nov, 2015.

17. Hamill J. Real-world evidence on asthma review and change from fluticasone propionate/salmeterol to fluticasone propionate/formoterol. Poster presented at the PCRS UK conference, 2014, UK.

18. Price D. Clinical effectiveness and cost impact in UK patients with asthma switching from fluticasone-propionate/salmeterol pMDI to fluticasone-propionate/formoterol pMDI. Primary Care Respir Med. 2015;25:15060. Abstract 51. 
19. Collar J. Treatment of moderate to severe persistent asthma in Spain: a model of the impact of the introduction of a combination of fluticasone proprionate/formoterol (flutiform). Poster presented at Jornadas de Economia de la Salud Granada, Spain, 2015, P-072.

20. Schmidt O, Kanniess F. Flutiform a combination in the treatment of asthma in real life setting. Intermediate results of a non-interventional study on safety and effectiveness. Poster presented at: Kongress der deutschen gesellschaft für pneumologie und beatmungsmedizine Bremen, Germany, 2014, P492.

21. Midlands Therapeutics Review and Advisory Committee (MTRAC). Commissioning support for fluticasone propionate/formoterol inhaler for the treatment of asthma. 2014. Available from: http://centreformedicinesoptimisation.co.uk/files/ Flutiform\%20update\%20VS\%202014_final.pdf. Dec, 2015.
22. Scottish Medicines Consortium. Fluticasone/ formoterol (Flutiform). 2012. Available from: http://www.scottishmedicines.org.uk/SMC_Advice/ Advice/736_11_fluticasone_formoterol_mdi_inhaler _Flutiform/fluticasone_formoterol_Flutiform. Oct, 2015.

23. National Institute for Health and Clinical Excellence (NICE). Technology appraisal guidance 138. Inhaled corticosteroids for the treatment of chronic asthma in adults and children aged 12 years and over. 2013. Available from: https:// www.nice.org.uk/guidance/ta138/resources/inhaledcorticosteroids-for-the-treatment-of-chronic-asthma -in-adults-and-in-children-aged-12-years-and-over-3 74751325. Dec, 2015. 